Г. В. Хомкалов

Байкальский государственный университет, г. Иркутск, Российская Федерация

И. Г. Торгашина

Байкальский государственный университет,

г. Иркутск, Российкая Федерация

К. В. Демьянов

OOO «Росгосстрах»,

2. Якутск, Российская Федераиия

\title{
ПЛАНИРОВАНИЕ ВОСПРОИЗВОДСТВА ЖИЛИЩНОГО ФОНДА В УСЛОВИЯХ НЕОПРЕДЕЛЕННОСТИ РЕГИОНАЛЬНОЙ ЭКОНОМИКИ
}

\begin{abstract}
АНнотАЦИЯ. В статье проанализирована взаимосвязь между основными формами воспроизводства жилищного фонда, используемыми в настоящее время для решения проблемы обеспеченности населения жильем. Выявлена разбалансированность между количественными показателями, определяющими необходимые объемы капитального ремонта, модернизации или реконструкции жилищного фонда, включая строительство нового жилья. Установлено и доказано негативное влияние состояния неопределенности на процесс воспроизводства жилищного фонда. Представлен авторский подход к решению проблемы обеспеченности населения жильем, основанный на использовании модели «сбалансированной системы показателей» в условиях возникающего состояния неопределенности. Предложено совместное использование вероятностных подходов и методов дифференциально-интегрального исчисления в предлагаемой модели с целью трансформации возникающего состояния неопределенности в полную или частичную определенность, позволяющее с достаточной степенью точности осуществлять комплексное прогнозирование необходимых объемов воспроизводства жилья.

КЛЮЧЕВЫЕ СЛОВА. Жилищная проблема; сбалансированные показатели; состояние неопределенности; обеспеченность жильем; комплексное решение; воспроизводство жилищного фонда.
\end{abstract}

ИНФОРМАЦИЯ О СТАТЬЕ. Дата поступления 25 января 2016 г.; дата принятия к печати 26 февраля 2016 г.; дата онлайн-размещения 30 марта 2016 г.

G. V. Khomkalov Baikal State University, Irkutsk, Russian Federation

I. G. Torgashina

Baikal State University, Irkutsk, Russian Federation

K. V. Demyanov JSC «Posgosstrakh», Yakutsk, Russian Federation

\section{PLANNING REPRODUCTION OF HOUSING FACILITIES IN TERMS OF UNCERTAINTY OF REGIONAL ECONOMY}

\begin{abstract}
The article analyses the interrelation between basic forms of reproducing housing facilities that are currently used for solving the problem of public housing per capita. It identifies the misbalance between quantitative indicators that determine necessary amounts of major repairs, modernization or reconstruction of the housing facilities, including construction of new housing. It states and proves the negative impact of the uncertainty situation on the process of reproducing the housing facilities.
\end{abstract}

\section{Baikal Research Journal}


It presents an authors' approach to solving the problem of public housing per capita, which is based on using the model of "balanced system of indicators" in terms of the arising situation of uncertainty. The article offers joint use of probabilistic approaches and methods of differential and integrational calculation in the proposed model aimed at transforming the arising situation of uncertainty into full or fractal certainty that will allow with a sufficient accuracy degree to accomplish a complex forecasting of the necessary mounts of housing reproduction.

KEYWORDS. Housing problem; balanced indicators; situation of uncertainty; housing per capita; complex solution; reproduction of housing facilities.

ARTICLE INFO. Received January 25, 2016; accepted February 26, 2016; available online March 30, 2016.

Выполнение программы расселения из ветхого жилья приобретает для руководителей регионов кроме социально-экономического и политическое значение. Так, за невыполнение показателей программы лишился должности губернатор Забайкальского края, а глава Карелии получил выговор [1]. По данным Фонда содействия реформированию жилищно-коммунального хозяйства, в 2015 г. площадь аварийного жилья составляла $2914400 \mathrm{~m}^{2}$ [2]. Следовательно, программа расселения из ветхого жилья как форма воспроизводства жилищного фонда позволяет, во-первых, увеличивать обеспеченность населения жилой площадью в стране, а во-вторых, замещать ветхий и аварийный фонд, имеющийся в регионах. На современном этапе развития общественных отношений процесс комплексного воспроизводства жилищного фонда является одним из основных инструментов, позволяющих достигать эффективного решения жилищной проблемы, возникающей среди населения регионов, обеспечивая ему комфортные и безопасные условия проживания. Однако на деле ситуация выглядит несколько иначе, поэтому для детального описания сложившейся ситуации в сфере воспроизводства жилищного фонда необходимо аналитическим путем установить тесноту взаимосвязи между основными показателями воспроизводства жилья на макроуровне.

Исследование статистической взаимосвязи между основными показателями воспроизводства жилья в общем по стране и конкретно по Иркутской области предлагается осуществить с использованием следующих, логически связанных между собой показателей:

- число семей, получивших жилые помещения, и количество введенного в строй жилья;

- объемы построенного жилья в регионах и уровень обеспеченности населения в них жилой площадью;

- объемами строительства жилья и уровень ветхого и аварийного фонда в стране.

Непосредственно для Иркутской области проанализированы следующие логические цепочки: первая характеризует связь между количеством ветхого и аварийного фонда по области и построенного жилья; вторая - объемы ветхого и аварийного фонда и капитально отремонтированного жилья.

Содержательная часть корреляционного анализа, проведенного в исследовании, заключается в установлении существенности статистической связи между показателями, воспроизводства жилья на макроуровне, оцениваемой по значению линейного коэффициента корреляции $r_{x y}$, определяемого на основании ретроспективных статистических данных. Принимая во внимание, что коэффициент корреляции представляет собой случайную величину с нормальным либо отличным от него законом распределения, предлагается для проверки гипотезы о существовании корреляционной связи между исследуемыми признаками и интервальной оценки линейного коэффициента корреляции $r_{x y}$ использовать статистическую функцию $z$-преобразование Фишера. Оценивание тесноты связи между исследуемыми пока-

\section{Baikal Research Journal}

электронный научный журнал Байкальского государственного университета 
зателями осуществляется в соответствии с математическими выражениями, вычисляемыми в табличном процессоре Excel [3]. Значение линейного коэффициента корреляции определяется следующим выражением:

$$
r_{x y}=\frac{n \sum x y-\sum x \sum y}{\sqrt{\left[n \sum x^{2}-\left(\sum x\right)^{2}\right]\left[n \sum y^{2}-\left(\sum y\right)^{2}\right]}},
$$

где $x, y$ - случайные исследуемые величины.

Качественная оценка тесноты связи между исследуемыми признаками осуществляется с использованием критериев шкалы Чеддока. Значение t-статистики Стьюдента, необходимое для проверки гипотезы $H_{o}$, констатирующей равенство линейного коэффициента корреляции нулю $\left(H_{o}: r_{x y}=0\right)$, вычисляется согласно следующей формуле:

$$
t_{p}=\frac{|r|}{\sqrt{1-r^{2}}} \sqrt{n-2},
$$

где $r$ - коэффициент корреляции; $n$ - размер выборочной совокупности.

Гипотеза $\left(H_{o}: r_{x y}=0\right)$ отвергается при соблюдении условия $t_{p}>t_{\kappa p}$, свидетельствующего о значимости линейного коэффициента корреляции, а следовательно, и существующей статистической зависимости между исследуемыми показателями. В ином случае $\left(t_{p}<t_{\kappa p}\right)$ гипотеза $H_{o}$ принимается, что указывает на отсутствие статистической зависимости между изучаемыми признаками. Табличное значение $t$-критерия Стьюдента $t_{\kappa p}$ берется из статистических таблиц исходя из величины уровня значимости $a$ и числа степеней свободы $k$. Интервальная оценка для статистически значимого линейного коэффициента корреляции $z$-преобразования Фишера вычисляется с использованием следующего выражения:

$$
z \in\left[z^{\prime} \pm z_{y} \sqrt{\frac{1}{n-3}}\right]
$$

где $z^{\prime}$ - значение, полученное на основе $z$-преобразования Фишера; $z_{y}$ - табулированное значение для стандартного нормального распределения с параметрами $y=1-a$.

Исходя из полученных значений $z$, границы отклонения линейного коэффициента корреляции $r_{x y}$ определяются с использованием функции обратного $z$-преобразования Фишера. Величина стандартной ошибки, возникающей при исчислении линейного коэффициента корреляции, определяется выражением

$$
\sigma_{y}=\sqrt{\frac{1-r^{2}}{n-2}} .
$$

Ретроспективная статистическая информация, включая результаты корреляционного анализа, представлена в приведенных далее таблицах. Непосредственно итоги оценивания тесноты связи между числом семей, получивших жилые помещения и объемами введенного в эксплуатацию жилья в стране, представлены в табл. 1.

Значения показателей, полученные в ходе исследования, позволяют сделать следующие выводы. Анализ связи между изучаемыми признаками показал на ее статистическую незначимость. Подобное положение дел вполне объяснимо ориентацией жилищной политики государства на коммерческую реализацию построенного жилья, включая жилье, возведенное в рамках социальных программ. Следовательно, несущественность связи между динамикой введенного в строй жилья и количеством лиц, получивших жилые помещения, позволяет судить о недостаточ-

\section{Baikal Research Journal}


ной эффективности используемых для этих целей мероприятий в результате низкой приоритетности данного направления в государственной жилищной политике.

Таблица 1

Число семей, получивших жилые помещения, и объемы возведенного жилья в России за 1990-2013 г2.

\begin{tabular}{|c|c|c|c|}
\hline Год & \begin{tabular}{|c|} 
Число семей, получив- \\
ших жилые помещения \\
и улучшивших свои \\
жилищные условия, ед. \\
\end{tabular} & $\begin{array}{c}\text { Ввод } \\
\text { домов, } \\
\text { млн м }^{2}\end{array}$ & Результаты корреляционного анализа \\
\hline 1990 & 1296 & 61,7 & Коэффициент корреляции $r_{x y}=0,129$ \\
\hline 2000 & 253 & 30,3 & Расчетное значение статистики Стьюдента $t_{p}=0,292$ \\
\hline 2005 & 151 & 43,6 & Табличное значение статистики Стьюдента $t_{\kappa p}=2,571$ \\
\hline 2010 & 244 & 58,4 & \multirow{4}{*}{$\begin{array}{l}t_{p}<t_{\text {pp }} \text {, следовательно, гипотезу } H_{0}: r_{x y}=0 \text { принима- } \\
\text { ем. Линейный коэффициент корреляции не значим, } \\
\text { поэтому и статистическая зависимость между числом } \\
\text { семей, получивших жилье и количеством построенно- } \\
\text { го жилья не существенная }\end{array}$} \\
\hline 2011 & 181 & 62,3 & \\
\hline 2012 & 186 & 65,7 & \\
\hline 2013 & 153 & 70,5 & \\
\hline
\end{tabular}

Составлено по: Российский статистический ежегодник. 2014 : стат. сб. М. : Росстат, 2014. С. $165,413$.

Исследование взаимосвязи между объемами введенного в эксплуатацию жилья и количеством общей площади, приходящейся в среднем на одного жителя в России, (табл. 2) указывают на ее статистическую незначимость. Подобная констатация дает основания полагать о существующей несбалансированности мероприятий, проводимых государством в рамках жилищной политики, в целях улучшения условий проживания российских семей. К примеру: в развитых европейских странах обеспеченность жилой площадью населения страны составляет от 40 до $60 \mathrm{~m}^{2}$, в США около $70 \mathrm{~m}^{2}$, а в России в среднем $23,4 \mathrm{~m}^{2}[4]$.

Таблица 2

Общая площадь, приходящаяся на одного жителя страны, и объемы строительства жилья в России за 1990-2013 г2.

\begin{tabular}{|r|r|r|l|}
\hline Год & $\begin{array}{c}\text { Объем } \\
\text { вводимого } \\
\text { жилья, млн м }\end{array}$ & $\begin{array}{c}\text { Общая площадь } \\
\text { на одного } \\
\text { жителя, }{ }^{2}\end{array}$ & Результаты корреляционного анализа \\
\hline 1990 & 61,7 & 16,4 & Коэффициент корреляции $r_{x y}=0,432$ \\
\hline 2000 & 30,3 & 19,2 & Расчетное значение статистики Стьюдента $t_{p}=1,071$ \\
\hline 2005 & 43,6 & 20,8 & Табличное значение статистики Стьюдента $t_{\kappa p}=2,571$ \\
\hline 2010 & 58,4 & 22,6 & $t_{p}<t_{\kappa p}-$ гипотезу $H_{0}: r_{x y}=0$ принимаем. Из чего \\
\hline 2011 & 62,3 & 23,0 & $\begin{array}{l}\text { следует, что линейный коэффициент корреляции не } \\
\text { значим, поэтому и статистическая зависимость между }\end{array}$ \\
\hline 2012 & 65,7 & 23,4 & показателем обеспеченности жильем населения и вве- \\
\hline 2013 & 70,5 & 23,4 & денным в эксплуатацию не существенная \\
\hline
\end{tabular}

Составлено по: Российский статистический ежегодник. 2014 : стат. сб. М. : Росстат, 2014. С. 165, 413.

Таким образом, принимая во внимание жилищные нормативы, а также учитывая интересы бизнеса и государства, для нормальных условий формирования человеческого капитала семья из четырех человек должна проживать в квартире общей площадью не менее $72 \mathrm{~m}^{2}$ [5-7]. В свою очередь подобное положение дел указывает на недостаточную обеспеченность жильем населения страны исходя из жилищных нормативов, интересов бизнеса и государства, а также по отношению к показателям европейских странах и США. Анализ тесноты связи между количеством введенного в стране жилья и величиной ветхого и аварийного фонда в регионах позволил сформулировать следующие заключения (табл. 3).

\section{Baikal Research Journal}


Объемы ветхого и аварийного фонда в сопоставлении с количеством построенного жилья в России за 1990-2013 г2.

\begin{tabular}{|c|c|c|c|}
\hline Год & $\begin{array}{c}\text { Фонд ветхого и } \\
\text { аварийного жилья, } \\
\text { млн м }^{2}\end{array}$ & \begin{tabular}{|c|} 
Ввод домов, \\
млн м
\end{tabular} & Результаты корреляционного анализа \\
\hline 1990 & 32,2 & 61,7 & Коэффициент корреляции $r_{x y}=0,219$ \\
\hline 2000 & 65,6 & 30,3 & Расчетное значение статистики Стьюдента $t_{p}=0,501$ \\
\hline 2005 & 94,6 & 43,6 & Табличное значение статистики Стьюдента $t_{\kappa p}=2,571$ \\
\hline 2010 & 99,4 & 58,4 & \multirow{4}{*}{$\begin{array}{l}t_{p}<t_{\kappa p}-\text { гипотезу } H_{0}: r_{x y}=0 \text { принимаем. Таким обра- } \\
\text { зом, линейный коэффициент корреляции не значим. } \\
\text { Следовательно, статистическая зависимость между } \\
\text { величиной ветхого и аварийного фонда и количеством } \\
\text { введенного в эксплуатацию жилья не существенна }\end{array}$} \\
\hline 2011 & 98,9 & 62,3 & \\
\hline 2012 & 99,9 & 65,7 & \\
\hline 2013 & 93,9 & 70,5 & \\
\hline
\end{tabular}

Составлено по: Российский статистический ежегодник. 2014 : стат. сб. М. : Росстат, 2014. С. 41, 166.

Согласно итогам корреляционного анализа исследуемая связь между динамикой введенного в строй жилья в стране и количеством ветхого и аварийного фонда в ней является статистически не значимой. Для сравнения, по данным Минстроя РФ на 2015 г., износ коммунальной инфраструктуры в стране более $60 \%$, а количество аварийных домов превысило 50 тыс. ед., что составляет порядка $3 \%$ от общего числа многоквартирных домов в стране ${ }^{1}$. Между тем в конце 1990 г. уровень ветхого и аварийного фонда не превышал значение в 1,3 \% от совокупной величины жилищного фонда в стране 2 . Вместе с тем порядка 650 тыс. многоквартирных домов (примерно 26 \% от общего жилищного фонда страны) требует капитального ремонта. Поэтому в целях улучшения сложившейся ситуации в жилищном секторе необходимо в первую очередь уделить внимание строительству новых жилых домов, а также процедуре капитального ремонта в эксплуатируемом жилищном фонде, в том числе за счет более активного участия малого и среднего предпринимательства [8]. Дополнительно к этому стоит отметить, что затраты на последующий капитальный ремонт вновь вводимого жилья напрямую будут зависеть от качества возведенных домов $[7 ; 9 ; 10]$. Однако в реальной ситуации отсутствие корреляции между исследуемыми показателями указывает на совершенно иную картину, свидетельствующую об увеличении объемов вводимого в эксплуатацию жилья с одновременным ростом ветхого и аварийного фонда, что при сбалансированной системе воспроизводства жилищного фонда не должно наблюдаться. Дальнейшее исследование тесноты связи между объемами капитально отремонтированного жилья в регионах и динамикой ветхого и аварийного фонда в стране показало следующие результаты (табл. 4).

Итоги корреляционного анализа с вероятностью 0,95 позволяют утверждать о существенной связи между объемами капитально отремонтированного жилья в стране и величиной ветхого и аварийного фонда в регионах. В соответствии со шкалой Чеддока значение линейного коэффициента корреляции, составившее $-0,84$ и находящееся в диапазоне от $-0,22$ до $-0,98$, позволяет охарактеризовать качество связи как высокую и обратную. Это означает, что при уменьшении объемов капитально отремонтированного жилья, уровень ветхого и аварийного фонда увеличивается. Подобная констатация указывает на целесообразность капитального ремонта жилых домов по отношению к варианту их безремонтной эксплуатации и замене на новый дом к моменту полной физической изношенности.

\footnotetext{
${ }^{1}$ В России создадут институт развития жилищной сферы // Российская газета. 2015. 5 июня.

${ }^{2}$ Российский статистический ежегодник. 2014. С. 166.
}

\section{Baikal Research Journal}


Площади капитально отрелонтированного жилья, включая ветхий и аварийный фонд в России за 1990-2013 22.

\begin{tabular}{|c|c|c|c|}
\hline Год & $\begin{array}{c}\text { Площадь жилья, } \\
\text { отремонтированного } \\
{\text { капитально, тыс. }{ }^{2}} \\
\text { общей площади }\end{array}$ & \begin{tabular}{|c|} 
Фонд ветхо- \\
го и аварий- \\
ного жилья, \\
млн м $^{2}$ \\
\end{tabular} & Результаты корреляционного анализа \\
\hline 1990 & 29103 & 32,2 & Коэффициент корреляции $r_{x y}=-0,835$ \\
\hline 2000 & 3832 & 65,6 & Расчетное значение статистики Стьюдента $t_{p}=3,395$ \\
\hline 2005 & 5552 & 94,6 & Табличное значение статистики Стьюдента $t_{\kappa p}=2,571$ \\
\hline 2010 & 8660 & 99,4 & \multirow{4}{*}{$\begin{array}{l}t_{p}>t_{\kappa p}-\text { гипотезу } H_{0}: r_{x y}=0 \text { отвергаем. Из чего } \\
\text { следует, что линейный коэффициента корреляции } \\
\text { является статистически значимым, следовательно, } \\
\text { и статистическая зависимость между исследуемыми } \\
\text { показателями существенна }\end{array}$} \\
\hline 2011 & 4326 & 98,9 & \\
\hline 2012 & 3995 & 99,9 & \\
\hline 2013 & 3045 & 93,9 & \\
\hline
\end{tabular}

Составлено по: Российский статистический ежегодник. 2014 : стат. сб. М. : Росстат, 2014. С. $165,166$.

В качестве частного примера исследованы взаимосвязи между показателями воспроизводства жилищного фонда в Иркутской области, позволяющие детально описать ситуацию с жильем в регионе (табл. 5).

Таблица 5

\section{Обеспеченность жильел и объемы вводилого жилья} в Иркутской области за 2000-2013 г2.

\begin{tabular}{|c|c|c|c|}
\hline Год & $\begin{array}{c}\text { Обеспеченность } \\
\begin{array}{c}\text { жильем, } \text { м }^{2} / \\
\text { чел. }\end{array} \\
\end{array}$ & 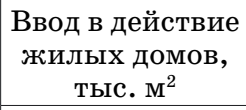 & Результаты корреляционного анализа \\
\hline 2000 & 18,8 & 185,8 & Коэффициент корреляции $r_{x y}=0,977$ \\
\hline 2005 & 20 & 302,5 & Расчетное значение статистики Стьюдента $t_{p}=9,210$ \\
\hline 2010 & 21,4 & 628,1 & Табличное значение статистики Стьюдента $t_{\kappa p}=2,776$ \\
\hline 2011 & 21,7 & 755,2 & \multirow{3}{*}{$\begin{array}{l}t_{p}>t_{\kappa p}, \text { следовательно, гипотезу } H_{0}: r_{x y}=0 \text { отвергаем. } \\
\text { Линейный коэффициент корреляции статистически } \\
\text { значим, что указывает на существенную статистиче- } \\
\text { скую зависимость между показателем обеспеченно- } \\
\text { сти жильем населения в регионе и вводом жилья по } \\
\text { области }\end{array}$} \\
\hline 2012 & 22,1 & 871,1 & \\
\hline 2013 & 22,3 & 973,3 & \\
\hline
\end{tabular}

Составлено по: Жилищно-коммунальное хозяйство Иркутской области. 2013 : стат. сб. Иркутск : Иркутскстат, 2014. С. 26.

Итоги проведенного анализа с вероятностью 0,95 дают основание полагать, что линейный коэффициент корреляции, составивший значение 0,977 и находящийся в диапазоне от 0,801 до 0,998 с величиной стандартной ошибки в 0,106 , указывает на статистическую значимость связи между исследуемыми признаками. Принимая во внимание критерии шкалы Чеддока, тесноту связи можно оценить как прямую и весьма высокую. Иными словами, при увеличении объемов строительства жилья в области возрастает и обеспеченность жилой площадью населения в регионе, поэтому данная форма воспроизводства жилищного фонда используется в качестве одного из ключевых инструментов для снижения актуальности жилищной проблемы региона. Стоит отметить, что в 1990 г. в Иркутской области было введено порядка 1512 тыс. м² жилья [11], а в 2014 г. - всего 717 тыс. м $^{2}$. Это свидетельствует о крайне низких объемах строительства жилых домов в регионе при растущей потребности населения в жилье. Дополняет картину, отражающую состояние дел в жилищной сфере, анализ взаимосвязи между динамикой ветхого и аварийного фонда и объемами строительства жилья по области (табл. 6).

\section{Baikal Research Journal}


Таблица 6

Ветхий и аварийный фонд в регионе и количество введенного жилья по годал

\begin{tabular}{|c|c|c|c|}
\hline Год & $\begin{array}{c}\text { Ввод в дей- } \\
\text { ствие жилых } \\
\text { домов, тыс. } \mathbf{m}^{2}\end{array}$ & $\begin{array}{c}\text { Ветхий и аварий- } \\
\text { ный жилищный } \\
\text { фонд, тыс. } \text { м }^{2}\end{array}$ & Результаты корреляционного анализа \\
\hline 2000 & 185,8 & 1520,1 & Коэффициент корреляции $r_{x y}=0,841$ \\
\hline 2005 & 302,5 & 3290,7 & Расчетное значение статистики Стьюдента $t_{p}=3,106$ \\
\hline 2010 & 628,1 & 4439,6 & Табличное значение статистики Стьюдента $t_{\kappa p}=2,776$ \\
\hline 2011 & 755,2 & 4589,3 & \multirow{3}{*}{$\begin{array}{l}t_{p}>t_{\kappa p}-\text { гипотезу } H_{0}: r_{x y}=0 \text { отвергаем. Линейный ко- } \\
\text { әффициент корреляции существенен, следовательно, и } \\
\text { статистическая зависимость между вводимым жильем } \\
\text { и ветхим и аварийным жилищным фондом значима }\end{array}$} \\
\hline 2012 & 871,1 & 4528,6 & \\
\hline 2013 & 973,3 & 4189,8 & \\
\hline
\end{tabular}

Составлено по: Жилищно-коммунальное хозяйство Иркутской области. 2013 : стат. сб. Иркутск : Иркутскстат, 2014. С. 26, 40.

Полученное значение линейного коэффициента корреляции 0,84 , находящегося в диапазоне от 0,092 до 0,982, характеризует исследуемую связь с вероятностью 0,95 , как статистически значимую. Оценка тесноты связи, основанная на использовании критериев шкалы Чеддока, позволяет заключить, что между исследуемыми признаками существует высокая статистическая зависимость. Из чего следует, что увеличение вводимого жилья в регионе не приводит к соответствующему снижению количества ветхих и аварийных зданий, что противоречит логике. Подобное положение дел еще раз указывает на разбалансированность в процессе планирования, финансирования и воспроизводства жилищного фонда, из чего следует заключение о низкой эффективности используемых мероприятий, ориентированных на улучшение существующей ситуации в регионе.

В настоящее время для решения жилищной проблемы в регионах планируется уделить особое внимание вопросам строительства нового жилья, включая жилье экономического класса в соответствие с федеральной целевой программой «Жилище». В связи с чем на эти цели 12 регионам РФ будет выделено порядка 3 млрд р. из средств федерального бюджета ${ }^{3}$. Дополнительно к этому планируется реализация мероприятий по расселению ветхого и аварийного фонда, включая работы по капитальному ремонту жилищного фонда.

Осуществление запланированных мероприятий планируется реализовать через модернизированную систему государственного заказа с привлечением средств ипотечного кредитования и частных инвестиций $[12$, с. 5]. Здесь необходимо отметить, что вопрос о финансировании запланированных мероприятий стоит остро. Причина такого положения дел заключается в использовании государством централизованного распределения средств в условиях недостаточно четко проработанного механизма рационального распределения ресурсов. Между тем в процессе формирования программ по сносу и замещению ветхого и аварийного фонда затрагивается тема о необходимости балансировать источники финансирования всех проектов, связанных с воспроизводством жилищного фонда. В итоге, Правительство РФ приходит к выводу о необходимости создания единой методологической системы, выстроенной по единым правилам, учитывающей территориальные особенности субъектов и существующие в них ресурсы. Подобная ориентация деятельности Минстроя России позволяет от ведомственных расценок, используемых в настоящее время, перейти к модернизированной системе ценообразования [Там же, с. 10].

${ }^{3}$ Правительство выделило 3 млрд рублей на строительство жилья в регионах // Российская газета. 2015. 8 авг.

\section{Baikal Research Journal}

электронный научный журнал Байкальского государственного университета 
Таким образом, сформулированные Минстроем России задачи по строительству нового и жилья для улучшения жилищных условий населения, включая ввод жилья экономического класса и арендных домов, работ по капитальному ремонту и модернизации зданий осуществляется по несбалансированной схеме, то есть определяется не через совокупный объем требуемого к воспроизводству жилья. Похожая картина наблюдается и в отношении количественного определения средств, необходимых на воспроизводство жилья и модернизации инфраструктуры жилищно-коммунального хозяйства, поэтому в российской практике четко прослеживается необходимость использования комплексного и сбалансированного подхода для решения жилищной проблемы, основанного на количественном определении необходимых объемов воспроизводства и требуемых на эти цели средств.

В итоге, применяемые государством меры жилищной политики представляют собой совокупность несбалансированных форм воспроизводства жилья, по результатам которых оценивается эффективность запланированных мероприятий. При этом положительной считается такая деятельность, изменения от действия которой позволяют достичь снижения актуальности решаемой проблемы. Таким образом, учитывая тесноту связи, установленную между различными показателями, характеризующими итоги воспроизводства жилья в целом, становится очевидным, что реализованные мероприятия не позволяют достичь ожидаемых результатов в решении данной проблемы. В качестве одной из таких причин выступает состояние неопределенности [13].

Состояние неопределенности, возникающее в момент планирования и начала реализации намеченных мероприятий, определяет ситуацию в таком виде, когда исход от ожидаемой деятельности достаточно точно не определен. При этом стоит четко понимать, что возникающее состояние неопределенности способно трансформироваться в полную или частичную определенность на этапе промежуточного или окончательного подведения итогов осуществляемой деятельности. В частности, $\Phi$. Найтом было предложено: тот вид неопределенности, который возможно оценивать с использованием аналитических методов исчисления - относить к категории рисков, а положение дел, когда исход предстоящих ожиданий не определим - считать состоянием полной неопределенности, представляющей нечто абстрактное и трудно поддающееся изучению и пониманию. Из чего следует, что определяемая аналитическим путем неопределенность является по своей сути риском, управляя которым становится возможным достигать ожидаемых результатов. Неизмеримое состояние считается полной неопределенностью, требующей времени на ожидание, с целью возможности оценить происходящие изменения ситуации [14, с. 10].

Разграничив неопределенность на риск, поддающийся аналитической оценке и управлению, и неопределенность, влияние которой не прогнозируемо, становится возможным объяснить природу происхождения качественно нового результата в запланированной деятельности, когда получаемый результат отличен от ожидаемого итога. В результате наличие ряда нерешенных социальных и институциональных задач указывает на имеющийся комплекс проблем, связанный с влиянием неопределенности, на исход ожидаемой деятельности, оказывающий негативное влияние на процесс воспроизводства жилищного фонда. Это объясняет невозможность достижения равновесного состояния между существующим на рынке жилья спросом и предложением за счет использования только детерминированных подходов. Дополнительно к этому недостаточная проработанность механизма привлечения частных инвестиций для финансирования работ по возведению жилья и несистематическое проведение капитальных ремонтов еще раз подтверждают существующую разбалансированность между используемыми формами воспроизводства жилищного фонда, поэтому в целях улучшения ситуации в жилищной сфере необходимо раз-

\section{Baikal Research Journal}

электронный научный журнал Байкальского государственного университета 
работать комплексную модель, позволяющую достигать трансформации возникающего состояния неопределенности в полную или частичную определенность за счет комплексного прогнозирования необходимых объемов воспроизводства жилья.

Разработанный и описанный в статье авторский подход позволяет обеспечить взаимосвязь между основными показателями воспроизводства жилья, включая определение динамики изменения жилищного фонда в целом, в условиях возникающего состояния неопределенности с целью удовлетворить потребности населения в жилье. Возможность инвестировать средства в строительную отрасль потребителями для решения жилищной проблемы указывает нам на необходимость предоставления на рынке строительных услуг и в сфере эксплуатации жилищного фонда совокупного предложения в виде ввода новых жилых площадей и снижения уровня ветхого фонда. По нашему мнению, применение разработанной модели «сбалансированной системы показателей» в целях комплексного решения жилищной проблемы в стране, позволит обеспечить процесс воспроизводства жилья с учетом потребности населения, формирующего функцию совокупного спроса. Дополнительно к этому необходимо учитывать параметры продолжительности жилищного инвестиционно-строительного цикла при прогнозировании объемов воспроизводства жилья в регионах [6; 15]. Предлагаемая комплексная модель «сбалансированной системы показателей» представлена следующим математическим выражением:

$$
S(t)=S_{0} e^{Q_{\text {socnp. }}{ }^{t},}
$$

где $S_{0}$ - размер общей площади жилищного фонда в начальный момент времени, $\mathrm{M}^{2} ; Q_{\text {восnр. }}-$ величина необходимого объема воспроизводства жилищного фонда, определяемая как суммирование всех элементов данного процесса; $t$ - период прогнозирования.

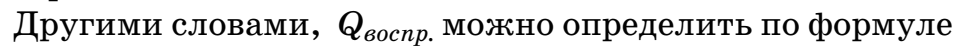

$$
\boldsymbol{Q}_{\text {воспр. }}=\frac{q_{\text {cmp. }}+q_{\text {кап.p. }}+q_{\text {мод. }}}{\bar{s}},
$$

где $q_{c m p .}$ - объем строительства, $\mathrm{m}^{2} ; q_{\kappa a n . p .}-$ объем капитального ремонта, $\mathrm{M}^{2} ; q_{\text {мод. }}-$ объем модернизации жилищного фонда, $\mathrm{m}^{2} ; \bar{s}-$ средний размер жилищного фонда за анализируемый период, $\mathrm{m}^{2}$.

Объемы строительства, капитального ремонта и модернизации жилищного фонда вычисляем по выражению

$$
q=\bar{s} p
$$

где $p$ - вероятность попадания случайной величины рассматриваемого элемента воспроизводства в диапазон отклонений за ретроспективный период времени.

При условии нормального распределения случайной величины значение вероятности определяется известным математическим выражением:

$$
p(a<x<b)=\Phi\left(\frac{b-\bar{x}}{\delta}\right)-\Phi\left(\frac{a-\bar{x}}{\delta}\right),
$$

где $p$ - искомая вероятность попадания случайной величины в заданный интервал; $\Phi((a-\bar{x}) / \delta)-$ уравнение функции нормального распределения.

В условиях, когда случайные величины количественно ограничены и совокупность их не соответствует нормальному закону распределения, величина показателей воспроизводства $q$ определяется с использованием теории «малых выборок»:

$$
q=S_{c p}+\left(t \mu_{m в}\right)
$$

где $S_{c p}-$ средний размер той площади элемента воспроизводства, распределение значений которого не соответствует условиям нормального закона распределения,

\section{Baikal Research Journal}


$\mathrm{M}^{2} ; t$ - коэффициент доверия, определяемый функцией обратного распределения Стьюдента; $\mu_{m \varepsilon}-$ мера случайных колебаний выборочной средней в малой выборке.

Использование модели «сбалансированной системы показателей» позволяет рассчитать необходимые объемы воспроизводства жилья для Иркутской области в условиях состояния неопределенности (табл. 7).

Планируемые объемы воспроизводства жилищного фонда

Таблица 7 для Иркутской области по годал $S(t)=S_{0} e^{Q_{\text {воспр. }}}$

\begin{tabular}{|c|c|c|c|c|}
\hline $\begin{array}{c}\text { Плановый } \\
\text { период } t, \text { годы }\end{array}$ & $e^{Q_{\text {esc } n \text {. }} t}$ & $S(t), \mathrm{M}^{2}$ & $S_{0-2013 \text { г. }}, \mathrm{M}^{2}$ & $Q_{\text {вocnp. }}, \mathrm{M}^{2}$ \\
\hline 1 & 1,24824247 & 67282141 & \multirow{7}{*}{53901500} & \multirow{7}{*}{0,22} \\
\hline 2 & 1,558109263 & 83984426 & & \\
\hline 3 & 1,944898155 & 104832928 & & \\
\hline 4 & 2,427704476 & 130856913 & & \\
\hline 5 & 3,030363831 & 163341156 & & \\
\hline 6 & 3,782628832 & 203889368 & & \\
\hline 7 & 4,721637955 & 254503368 & & \\
\hline
\end{tabular}

Разработанный и предложенный подход, основанный на использовании модели «сбалансированной системы показателей» в условиях возникающей неопределенности, позволяет применять рассмотренную модель в различных ситуациях, возникающих в ходе комплексного решения проблем воспроизводства жилищного фонда. При этом совместное использование вероятностных подходов и методов дифференциально-интегрального исчисления дает возможность вычислить необходимые объемы требуемого жилья в условиях возникающей неопределенности, определить планируемые затраты при проведении капитального ремонта, модернизации или реконструкции жилищного фонда, включая строительство нового жилья, а также обосновать распределение средств на финансирование и достичь равновесия между возникающим спросом и существующим предложением на рынке жилья.

\section{Список использованной литературы}

1. Латухина К. Ответили за ветхие метры / К. Латухина // Российская газета. - 2016. 17 февр.

2. Кузьмин В. 180 тысяч россиян расселят из аварийного жилья в 2015 году / В. Кузьмин // Российская газета. - 2015. - 9 янв.

3. Макарова Н. В. Статистика в Excel / Н. В. Макарова, В. Я. Трофимец. - М. : Финансы и статистика, 2002. - 368 с.

4. Развитие Российского общества: социально-экономические и правовые исследования / О. В. Батурина [и др.] ; под ред. М. А. Винокурова, А. П. Киреенко, С. В. Чупрова. - М. : Наука, 2014. - $622 \mathrm{c}$.

5. Грушина О. В. Доступность жилья как особая характеристика экономической системы государства / О. В. Грушина // Известия Иркутской государственной экономической академии. - 2011. - № 6 (80). - С. 140-146.

6. Светник Т. В. Корректировка стратегий строительства жилья в условиях кризиса / Т. В. Светник // Известия Иркутской государственной экономической академии. - 2015. T. 25, № 6. 一 C. 941-946. - DOI : 10.17150/1993-3541.2015.25(6).941-946.

7. Цвигун И. В. Развитие методологии управления качеством процессов в жилищной сфере / И. В. Цвигун, С. А. Астафьев. - Иркутск : Изд-во БГУЭП, 2011. - 275 с.

8. Киреенко А. П. Применение программно-целевого метода для государственной поддержки малого и среднего предпринимательства в регионах Сибирского федерального округа / А. П. Киреенко, Л. В. Санина // Известия Иркутской государственной экономической академии. - 2014. - № 4 (96). - С. 117-132.

\section{Baikal Research Journal}


9. Астафьев С. А. Обеспечение удовлетворенности потребителей продукции и услуг строительной и жилищной сферы за счет повышения качества системы саморегулирования / С. А. Астафьев. - Иркутск : Изд-во БГУЭП, 2012. - 193 с.

10. Чернышов Л. Н. Капитальный ремонт многоквартирных домов: проблемы формирования и направления развития / Л. Н. Чернышов, С. А. Астафьев, В. П. Вакулина // Известия Иркутской государственной экономической академии. - 2015. — Т. 25, № 1 . C. 85-94. — DOI : 10.17150/1993-3541.2015.25(1).85-94.

11. Винокуров М. А. Экономика Иркутской области : в 6 т. / М. А. Винокуров, А. П. Суходолов. - Иркутск : Изд-во БГУЭП, 2009. - Т. 6. - 291 с.

12. Мень М. А. О деятельности Минстроя России в 2014 г. и задачах на 2015 г. и среднесрочную перспективу / М. А. Мень // ЖКХ: журнал руководителя и главного бухгалтера. 2015. - № 6, ч. II. - С. 5 .

13. Чупров С. В. Особенности управления инновационной реиндустриализацией в нестационарной среде региональной экономики / С. В. Чупров // Известия Иркутской государственной экономической академии. - 2015. — T. 25, № 5. - С. 767-774. - DOI : 10.17150/1993-3541.2015.25(5).767-774.

14. Найт Ф. Риск, неопределенность и прибыль / Ф. Найт. - М. : Дело, 2003. - 173 с.

15. Амбросов Н. В. Управление и самоорганизация в экономике и отраслях промышленности / Н. В. Амбросов. - Иркутск : Изд-во БГУЭП, 2007. - 251 с.

\section{References}

1. Latukhina K. Got liable for ramshackle square meters. Rossiiskaya Gazeta, 2016, February 17 . (In Russian).

2. Kuzmin V. 180 thousand Russians will be relocated from emergency housing in 2015. Ros siiskaya Gazeta, January 9, 2015. (In Russian).

3. Makarova N. V., Trofimets V. Y. Statistika v Excel [Statistics in Excel]. Moscow, Finansy i statistika Publ., 2002. 368 p. (In Russian).

4. Baturina O. V. et al.; Vinokurov M. A., Kireyenko A. P., Chuprov S. V. (eds). Razvitie Rossiiskogo obshchestva: sotsial'no-ekonomicheskie i pravovye issledovaniya [Development of Russian society: socio-economic and legal investigations]. Moscow, Nauka Publ., 2014. 622 p.

5. Grushina O. V. Housing affordability as a feature of national economic system. Izvestiya Irkutskoy gosudarstvennoy ekonomicheskoy akademii = Bulletin of Irkutsk State Economics Academy, 2011, no. 6 (80), pp. 140-146. (In Russian).

6. Svetnik T. V. Adjusting strategies of housing construction in terms of crisis. Izvestiya Irkutskoy gosudarstvennoy ekonomicheskoy akademii = Bulletin of Irkutsk State Economics Academy, 2015, vol. 25. no. 6, pp. 941-946. DOI: 10.17150/1993-3541.2015.25(6).941-946. (In Russian).

7. Tsvigun I. V., Astafyev S. A. Razvitie metodologii upravleniya kachestvom protsessov $v$ zhilishchnoi sfere [Developing methodology of managing quality of processes in housing sector]. Irkutsk, Baikal State University of Economics and Law Publ., 2011. 275 p.

8. Kireyenko A. P., Sanina L. V. Application of program-targeted method for governmental support of small and medium-sized businesses in the regions of the Siberian Federal District. Izvestiya Irkutskoy gosudarstvennoy ekonomicheskoy akademii = Bulletin of Irkutsk State Economics Academy, 2014, no. 4, pp. 117-132. (In Russian).

9. Astafyev S. A. Obespechenie udovletvorennosti potrebitelei produktsii i uslug stroitel'noii zhilishchnoi sfery za schet povysheniya kachestva sistemy samoregulirovaniya [Making provisions of complacency for consumers of products and services of construction and housing sectors at the expense of improving quality of self-regulation system]. Irkutsk, Baikal State University of Economics and Law Publ., 2012. $193 \mathrm{p}$.

10. Chernyshov L. N., Astafyev S. A., Vakulina V. P. Apartment buildings capital repairs: funding problems and development trends. Izvestiya Irkutskoy gosudarstvennoy ekonomicheskoy akademii = Bulletin of Irkutsk State Economics Academy, 2015, vol. 25, no. 1, pp. 85-94. DOI: 10.17150/1993-3541.2015.25(1).85-94. (In Russian).

11. Vinokurov M. A., Sukhodolov A. P. Ekonomika Irkutskoi oblasti [Economy of Irkutsk Oblast]. Irkutsk, Baikal State University of Economics and Law Publ., 2009. Vol. 6. 291 p.

12. Men M.A. On activities of Russia's Ministry of Construction in 2014 and tasks for 2015 and the medium-term prospect. Zhilishchno Kommunal'noye Khozyaystvo: zhurnal rukovodite-

\section{Baikal Research Journal}


lya $i$ glavnogo bukhgaltera $=$ Housing and Communal Services: Journal of Executor and Chief Accountant, 2015, no. 6, pr. II, pp. 5. (In Russian).

13. Chuprov S. V. Features of innovative industrialization management in regional economic non-stationary environment. Izvestiya Irkutskoy gosudarstvennoy ekonomicheskoy akademii $=$ Bulletin of Irkutsk State Economics Academy, 2015, vol. 25, no. 5, pp. 767-774. DOI: 10.17150/1993-3541.2015.25(5).767-774. (In Russian).

14. Khight F. H. Risk, uncertainty, and profit. Hart, Schaffner \& Marx; Boston: Houghton Mifflin Company, The Riverside Press, Cambridge. 1921. (Russ. ed.: Khight F. H. Risk, neopredelonnost' i pribyl'. Moscow, Delo Publ., 2003. 173 p.).

15. Ambrosov N. V. Upravlenie i samoorganizatsiya v ekonomike i otraslyakh promyshlennosti [Management and self-organization in economy and industrial sectors]. Irkutsk, Baikal State University of Economics and Law Publ., 2007. 251 p.

\section{Информация об авторах}

Холкалов Геннадий Владимирович - доктор экономических наук, профессор, кафедра экономики и управления инвестициями и недвижимостью, Байкальский государственный университет, 664003, г. Иркутск, ул. Ленина, 11, e-mail: hgv@isea.ru.

Торгашина Ирина Геннадьевна - кандидат экономических наук, доцент, кафедра экономики и управления инвестициями и недвижимостью, Байкальский государственный университет, 664003, г. Иркутск, ул. Ленина, 11, e-mail: hig06@mail.ru.

Дельянов Константин Васильевич - кандидат экономических наук, менеджер, ООО «Росгосстрах», 677000, Республика Саха (Якутия), г. Якутск, ул. Пушкина, 10, e-mail: sq11979@rambler.ru.

\section{Authors}

Gennady V. Khomkalov - Doctor habil. in Economics, Professor, Chair of Economics and Investment and Real Estate Management, Baikal State University, 11 Lenin St, 664003, Irkutsk, Russian Federation; e-mail: hgv@isea.ru.

Irina G. Torgashina - PhD in Economics, Associate Professor, Chair of Economics and Investment and Real Estate Management, Baikal State University, 11 Lenin St, 664003, Irkutsk, Russian Federation; e-mail: hig06@mail.ru.

Konstantin V. Demyanov - PhD in Economics, Manager, JSC «Rosgosstrakh», 10 Pushkin St., 677000, Yakutsk, Russian Federation; e-mail: sql1979@rambler.ru.

\section{Библиографическое описание статьи}

Хомкалов Г. В. Планирование воспроизводства жилищного фонда в условиях неопределенности региональной экономики / Г. В. Хомкалов, И. Г. Торгашина, К. В. Демьянов // Baikal Research Journal. — 2016. — T. 7, № 2. — DOI : 10.17150/2411-6262.2016.7(2).8.

\section{Reference to article}

Khomkalov G. V., Torgashina I. G., Demyanov K. V. Planning reproduction of housing facilities in terms of uncertainty of regional economy. Baikal Research Journal, 2016, vol. 7, no. 2. DOI: 10.17150/2411-6262.2016.7(2).8. (In Russian).

\section{Baikal Research Journal}

